\title{
REFERENCES
}

1. Fuchs, E.-Kl. Miszellen, Arch.f. Augenheilk., Vol. XV. 1885.

2. Fuchs, E.-Zur Physiologie und Pathologie des Lidschlusses. Arch. $f$. Ophthal., Vol. XXXI, II. 1885.

3. VON HERRENSHWAND; F.-Ueber Ectropium conjunctivae palpebral congenitùm. Klin. Monatsbl. f. Augenheilk., Vol. LVI, p. 509. 1916.

4. Urmetzer, J.-Ein Fall von abnormer Kuerze der Lider. Klin. Monatsbl. f. Augenheilk., Vol. LIII, p. 240. 1914.

5. KuнNT-Ueber Distichiasis (congenita) vera Zeitschr. f. Augenheilk. Vol. I, p. 46. 1899.

6. BraIleX-Congenital distichiasis. Trans. Ophthal. Soc. U.K., Vol. XXVI, p. 16. 1906.

7. ERDMANN-Ein Beitrag zur Kenntnis der Distichiasis congenita (hereditaria). Zeitschr.f. Augenheilk., Vol. XI, p. 427. 1904.

8. SCHREIBER, L.-Die Krankbeiten der Augenlider. Handb. d. ges, Augenheilk. Graefe-Saemisch, pp. 358 and 573. 1924.

9. Fuchs, E.-Lehrbuch der Augenheilk., p. 637. 1905.

10. AUBARET, E.-Traité d'Ophtal., p. 862. 1919.

\section{RESEARCH IN ZURICH}

"Summary of the work on the pathological changes in the aqueous-humour and the blood-aqueous barrier, at Zurich." *

\author{
BY \\ M. J. ROPER-HaLi, D.O.M.S. \\ BIRMINGHAM
}

THE research at present being carried out at the University Augenklinik at $Z$ urich is devoted to the study of the aqueous humour and the blood-aqueous barrier.

This work was started by Professor Marc Amsler and his associates in Lausanne in 1940, and was mainly concerned with the albumen and cell-content of the aqueous in disease of the anterior segment. Since the Professor's appointment as Director the work has been continued and augmented at this clinic.

\section{The aqueous humour}

The specimen of aqueous humourisobtained in the following way:A smear and culture are taken from the conjunctival sac. The lids are then held open by a speculum, and a small scraping of corneal epithelium is taken from the lower and outer part of the cornea about three millimetres from the limbus. This area is painted with 5 per cent. iodine solution. The eye is now fixed by an assistant, and a puncture made through the painted area in a plane parallel to the iris. This puncture is made with a special needle devised by Professor Amsler which is placed on a 1 c.c. (tuberculin) syringe.

- Received for publication, January 29, 1947. 
The aqueous is then slowly withdrawn, and the needle removed in the same plane as that of its insertion.

This relatively simple procedure can easily be performed in the out-patient department.

The following investigations are made on the specimens obtained.

The conjunctival smear is examined after staining, and the state of the cells noted. The result of the conjunctival culture is correlated with the findings in the culture of the aqueous. The cell scraping of the corneal epithelium is also examined microscopically. A drop of the aqueous is used in the Pandy reaction (this reaction for the quantitative detection of albumen being selected for its reasonably accurate clinical results on small specimens). Another drop is placed in a counting cell (Fuchs-Rosenthal) to give a true figure of the cells $/ \mathrm{mm}^{3}$. A culture is taken in a broth medium (Rosenow). The remaining fluid is placed in a capillary centrifuge tube in which the centrifuged matter is deposited on a cover-glass; this specimen is stained with the May-Grunwald and Giemsa reagents and mounted, the slide is then examined to ascertain the type of cell present. If there is sufficient fluid a specimen is also stained by Gram's method.

All this has to be carried out on one-fifth of a c.c. of fluid or less, and the apparatus used is adapted for these minute quantities.

These examinations were controlled by an investigation of 300 normal eyes.

Serum reactions were carried out on a few cases early in the series, but were given up on account of the greater need for the fluid in other investigations. It was found that the W.R. in the aqueous is never positive if the blood reaction is negative, and even with a positive blood reaction unless there is albumen present the result is negative.

So far just over 1900 a.c. punctures have been performed in the course of this research.

\section{Findings}

1. In accord with other authors who have studied this question, it has been found that the normal aqueous contains between 0 and $1 \mathrm{cell} / \mathrm{mm}^{3}$.

2. In anterior uveitis and deep ulcers of the cornea, the number of cells is increased in varying proportions. The figures most often obtained vary between 30 and 200 cells $/ \mathrm{mm}^{3}$. A few cases rise even to 100,000 cells $/ \mathrm{mm}^{3}$.

3. In acute inflammations, the albumens are increased in proportion to the number of cells.

4. In chronic inflammations and other diseases it has been found constantly that there is a dissociation between the albumens and the cells, comparable to that observed in the pathology of the cerebrospinal fluid. 
5. The researches on the morphology and origin of the cells has proved that they are derived from the blood and the neighbouring tissues. The predominant rôle of the reticulo-endothelial system in a great number of cases of chronic irido-cyclitis has been noticed.

6. The phagocytic and antitoxic function of the cells desquamated into the anterior chamber has been indicated by the presence of micro- and macrophages in the specimens.

7. Out of 651 cases of exogenous and endogenous irido-cyclitis, keratitis and panophthalmitis, 19 per cent. showed large reticuloendothelial cells which had phagocytosed micro-organisms. Those that were most commonly seen were cocci with variable morphology and staining-thought to be staphylococci in most cases. In perforating wounds one may find Morax-Axenfeld bacilli and pseudodiphtheroids. Tubercle bacilli have never been found, except in one unusual case in which a- positive culture was obtained.

Cultures are very rarely positive (about 3 per cent.) even with strongly positive smears. Altogether the cultures have consisted of

7 Staph. albus.

1 Staph. aureus.

3 Pneumococcus.

1 Streptococcus.
1 Tubercle bacillus

1 Morax-Axenfeld bacillus.

6 Pseudo-diphtheroids and other unidentified organisms.

8. The presence of micro-organisms in the anterior chamber in the course of keratitis and anterior uveitis throws a light on the aetiology in many cases.

9. The absence of tubercle bacilli in the numerous specimens studied causes doubt as to the preponderant rôle which is attributed to them in the pathogenesis of chronic uveitis, especially as other microbes have been found.

10. The phagocytosed micro-organisms which have been found have indicated the possibility of focal infection, and in many cases a focus has been found suggesting a strong aetiological factor.

\section{The blood-aqueous barrier}

Following the work of Ehrlich in 1881 on the use of intra-venous fluorescein (when he noticed that the dye found its way into the anterior chamber); this method has been adapted to the needs of the research here on the permeability of the blood-aqueous wall.

The flourescein is injected intra-venously and relative measurements of its concentration are taken at suitable time intervals during the next 30 minutes.

This is done by means of an adapted slit-lamp in which the illumination of the anterior chamber can be reduced by a resistance while the eye is kept under observation, until the green colouration of the aqueous is no longer detectable. Readings are then taken from an amperemeter in the slit-lamp circuit. 
These readings are plotted on a chart in graph form; time/amps resistance over a period of half an hour.

A preliminary investigation was carried out on 200 normals. These were carefully selected from individuals in which there was no evidence of ocular or general disease.

The results in these cases show that:-

1. There is a normal excretion of the dye into the anterior chamber. The analysis of the 200 cases shows that there is a regular and gradual rise of fluorescein concentration during the time of examination.

2. The permeability curves of the two normal eyes of an individual are the same.

3. The day to day variations in a normal eye are well within the limits of the normal band.

4. The normal for children up to about 15-17 years, is a little higher than the normal band for adults.

This research was then directed to the study of the altered permeability in disease, at first only in ocular disease, but more recently in cases with general diseases.

More than 1,000 patients have been examined in this way. The pathological curves of increased permeability are situated above the normal band and are characterised by an immediate rapid rise of concentration to a point where the concentration remains almost unaltered.

The findings in disease are as follows:-

1. Irido-cyclitis. All degrees of permeability increase, from the slightest forms to the most severe are seen, corresponding to the severity of the irido-cyclitis. There is a possibility of early diagnosis in cases where no other sign is visible. A control can be made of therapeutic effect on the permeability.

2. Glaucoma simplex. Some cases show normal or slightly increased permeability, while others show a considerable rise in permeability., It is possible that these alterations in the findings show a differentiation between true simple glaucoma and those tending to an inflammatory aetiology (on these points one's treatment may be altered).

3. Traumata. Contusion and perforating injuries produce a great increase of permeability. It can be seen in cases of unilateral injury, that there is a bilateral rise of permeability although the uninjured eye shows a less marked increase.

4. Other ocular affections causing an increased permeability. As examples: central venous thrombosis, periphlebitis, retinal detachment, choroiditis.

5. General diseases showing an increased permeability (with no sign of ocular inflammation). Bronchial asthma, gastric ulcer, generalised oedema, chronic nephritis, epidemic hepatitis, rheumatic 
polyarthritis, obesity, and above all diabetes (40 per cent.), and malignant hypertension. In purpura there is some parallelism between increased permeability and the Rumpel-Leed phenomenon.

6. Pharmacological effects. The pharmacological effects of some drugs commonly used in eye treatment, or which are known to have an effect on the capillary permeability in other parts of the body, have been studied. It has been found that pilocarpine increases the permeability, atropine and homatropine have no effect, adrenalin and l-glaucosan diminish the permeability. Subconjunctival injections of slightly hypertonic sodium chloride increase the permeability, calcium injected intra-venously in a dose of 10 c.c. of a 20 per cent. solution in many cases has a diminishing effect. Sub-cutaneous histamine in small doses has an enormously increasing effect.

\section{The Tyndall effect}

Since this work was taken up at Zurich, further aspects have been enquired into.

The beam of light from a slit-lamp passing through a proteinaceous aqueous in the anterior chamber shows itself in a flare described by Tyndall in 1869, and called the Tyndall effect.

This can be used as a clinical sign in diagnosis and prognosis of infections of the anterior segment. The Tyndall effect is more marked the higher the protein content of the aqueous and this is measured by a Tyndall photometer. This also is a modified slitlamp in which part of the illumination is reflected through a pair of crossed polarising filters to the microscope. On looking through the eye-piece one sees an oblong strip of light the brightness of which can be adjusted by rotation of one of the filters.

The image of the slit-lamp beam passing through the aqueous is seen immediately above the polarised image. The latter is adjusted until the appearance of both images is identical, and an average of four readings taken.

The results can be plotted on a graph (the Tyndall Nephelogram) giving an accurate record of the variations of the phenomenon.

-When plotted against time the graph will show a rise and fall which corresponds closely to the clinical deterioration and improvement, the more useful because of the early appearance of this sign in disease of the anterior segment.

In comparing the uses of the Tyndall effect with that of the fluorescein permeability, we see that the Tyndall effect shows the permeability of the damaged blood-aqueous barrier to proteins and large molecules; while the fluorescein permeability shows the more minute changes in the permeability of the wall to smaller particles. Secondly, whereas the normal barrier will not allow a positive 
Tyndall effect, it will allow fluorescein to pass through. Thus the fluorescein will give an earlier and more sensitive impression. i! bi

The most recent trends here are aimed at finding out the effect of pathological aqueous on a tissue culture of fibrocytes. It is suspected from clinical observations that the pathological humour will have a detrimental effect on these cells. The work has only just commenced (November, 1946) and no results are available yet.

The aqueous is now also being examined under the ultramicroscope to study the cells, bacteria, and the number and size of the protein particles.

\section{BIBLIOGRAPHY}

Amsler, M. et VerRey, Fl.-De l'utilité pratique de la ponction de la chambre antérieure. Ophthalmologica, Vol. CV, Nr. 3/4 (1943).

VERREY, FLORIAN. - Un dispositif pour la centrifugation capillaire. Ophthalmologica, Vol. CV, No. $3 / 4$ (1943).

VERREY, FL. ET RENE DUFOUR.-Quelques aspects cytologiques de l'bumeur aqueuse dans les uvéites. Ophthalmologica, Vol. CVII, No. 1/2 (1944).

VERREY, FLORIAN.-Etude des éléments figurés de l'humeur aqueuse pathologique. - Librairie médicale F. Roth et Cie, Laus.

AMSLER, M. ET VERREY, FL.-Hétérochromie de Fuchs et fragilité vasculaire. Ophthalmologica, Vol. CXI, No. 2/3 (1946).

VERREY, FLORIAN.-Signification pratique de la phagocytose intraoculaire. Ophthalmologica, Vol. CXI, No. 4/5 (1946).

AMSler, M. und HUBER, A.-Methodik und erste klinische Ergebnisse einer Funktionsprüfung der Blut-Kammerwasserschranke. Ophthalmologica, Vol CXI, No. $2 / 3$ (1946).

HaEfeli, Walter.-Die Fluorescein-Permeabilität der Blut-KammerwasserSchranke des gesunden Auges. Ophthalmologica, Vol. CXII, No. 4/5 (1946).

Huber, AlFRED.-Zum Tyndallphänomen in der Augenvorderkammer. Ophthalmologica, 1947.

Zur Pharmakologie der Blut-Kammerwasser-Schranke. Ophthalmologica, 1947.

\section{A GRÖNBLAD-STRANDBERG SYNDROME*}

BY

DR. SÜREYYA GÖRDÜREN

PROFESSOR OF OPHTHALMOLOGY, UNIVERSITY OF ANKARA

ANGIOID streaks are a rare form of retinal degeneration and are recognisable by a network of streaks varying in colour from reddish to dark brown. The two components of the syndrome, that is, angioid streaks and pseudo-xanthoma elasticum could be clearly seen in our case. It is suggested that in this disease there is a degeneration of the elastic tissues throughout the body.

* Received for publication, January 18, 1947. 